\title{
Effectiveness of Protective Measures in Reducing Risk of Radiation Exposure in Interventional Pain Management: A Prospective Evaluation
}

\author{
Laxmaiah Manchikanti, MD, Kim A. Cash, RT, Tammy L. Moss, RT, and Vidyasagar Pampati, MSc
}

It is estimated that over $50 \%$ of approximately 4 million interventional procedures performed annually in the United States are performed utilizing fluoroscopy. Fluoroscopy offers validity to interventional techniques by providing precise localization of anatomic target areas and facilitating accurate delivery of injectate. Exposure to ionizing radiation is an unavoidable consequence while performing fluoroscopic procedures. The primary source of radiation to the physician during interventional procedures is from scatter reflected back from the patient.

Multiple investigators have prospectively evaluated radiation exposure to the physician performing fluoroscopically guid- ed interventional procedures in various settings, with varying results.

This prospective controlled study was undertaken to evaluate scatter radiation risk of whole body exposure and protective measures to reduce scatter radiation in the upper and lower parts of the body in fluoroscopically guided interventional techniques. Five hundred consecutive patients, undergoing interventional procedures, in an ambulatory surgery setting were studied. The mode utilized varied from pulsed-imaging to continuous fluoroscopic imaging. All the protective measures were incorporated, including lead shielding from the table to the floor covering the entire area of the beam. Scat- ter radiation exposure was monitored in 5 areas with 3 badges inside the apron and 2 outside the apron.

Results of this study showed an average exposure per patient of $8.9 \pm 0.4$ seconds and per procedure of $4.9+0.11$ seconds. Scatter radiation exposure was higher outside the lead aprons compared to inside the lead aprons. Scatter radiation exposure at groin level was similar with or without lead shielding from the table to the floor.

Keywords: Interventional pain management, fluoroscopy, C-arm, radiation exposure, radiation toxicity, scatter radiation, maximum permissible dose, as low as reasonably achievable (ALARA)
C-arm fluoroscopy with image intensification is frequently utilized in performing many interventional pain management procedures and is becoming a routine practice in interventional pain management in the modern era. It is estimated that over $50 \%$ of approximately 4 million interventional procedures performed annually in the United States are performed utilizing fluoroscopy (1-5). In interventional pain management, fluoroscopy offers face validity of many types of diagnostic and therapeutic procedures by providing precise localization of anatomic target areas, and by facilitating accurate delivery of injectate (6-15). While C-arm fluoroscopy is not only considered as an integral part of interventional pain management, but is considered as a safe modality. Indeed, it is associated with risks of radiation exposure, not only to the physician, but also the patient and the per-

From Pain Management Center of Paducah, Paducah, Kentucky. Address Correspondence: Laxmaiah Manchikanti, MD, 2831 Lone Oak Road, Paducah, Kentucky 42003. E-mail: drm@apex.net Funding: There was no external funding in preparation of this manuscript. sonnel in the operating room or procedure room. The major advantage of interventional procedures in the management of chronic pain is that it requires fluoroscopic exposure for only short periods of time.

Exposure to ionizing radiation is an unavoidable event while performing fluoroscopic procedures. Since the only accurate way it can be avoided is to avoid the radiation, the other alternative is to minimize its absorption by biologic tissues. The primary source of radiation to the physician during interventional procedures is from scatter reflected back from the patient. Another source of radiation is radiation leakage from the equipment, however, this is of a lesser concern. The fundamental principles of radiation protection include: 1) maximization of distance from the radiation source, 2) liberal use of shielding materials, and 3) minimizing exposure time. Multiple dose reduction techniques have been described to include intermittent fluoroscopy, removal of grid, last image holding, electronic collimation, dose spreading, ad- justment of beam quality, image magnification, dose level settings, pulsed fluoroscopy, and appropriate training of fluoroscopy operators. Finally, the application of the concept of ALARA (as low as reasonably achievable) will keep radiation within the recommended and safe limits.

Radiation risks to the physician and assisting personnel are evaluated using the maximum safe allowable exposure limits which have been established by the $\mathrm{Na}$ tional Council on Radiation Protection (16). The current estimation of risk from radiographic exposure to a specific body part is based on the biologic effects of whole body exposure converted by weight factors, specific for individual organs and tissues. The International Commission on Radiological Protections in 1991 adapted specific organ risks (17). In addition, in 1994, the Center for Devices and Radiological Health of the Food and Drug Administration (FDA) issued an advisory, warning healthcare facilities of the potential for radiation-induced burns to patients from prolonged fluoroscopic procedures (18). While this advisory was issued 
specifically for patients, the same warning is also applied to physicians and other staff members of the team. The major risk for physicians with radiation exposure is related to the exposure due to the cumulative effect. According to the FDA advisory (18), a number of interventional procedures (not pain management), including radio-frequency cardiac catheter ablation, percutaneous transluminal angioplasty, vascular embolization, stent and filter placement, thrombolytic and fibrinolytic procedures, percutaneous transhepatic cholangiography, endoscopic retrograde cholangiopancreatography, transjugular intrahepatic portosystemic shunt placement, percutaneous nephrostomy, and biliary drainage or urinary or biliary stone removal are considered as high risk procedures (19).

Interventional pain management, as an evolving specialty, is in its infancy in reporting the various issues related to radiation exposure and complications secondary to the exposure. However, a number of case histories of injuries to both patients (20-22) and physicians (24) have been reported in other areas. Even then, the actual extent of the problem is essentially unknown either in general or specifically in interventional pain management settings. Currently, there are no requirements for reporting such information to the FDA and there is no central repository to provide such information in the United States. Multiple investigators have prospectively evaluated radiation exposure to the physician performing fluoroscopically guided interventional procedures in various settings $(7-10,15)$. Multiple evaluations showed low exposure rates in the upper part of the body $(7,8,10)$, except for two evaluations $(9,15)$, which showed significant exposure to the lower part of the body. Schade (9) and Manchikanti et al (15) measured radiation exposures to the lower part and upper parts of the body. Manchikanti et al (15) showed no exposure to scatter radiation in the upper part of the body in 509 patients, however, with significant exposure seen in the lower part of the body with a total of $15 \mathrm{mREM}$ scatter radiation with exposure of 0.0294 mREM exposure per patient. However, this study has not utilized any extra protection to protect the groin area by utilizing extra shielding either on the patient or from the table to the floor. The physician has followed all the principles utilized to reduce the dosage of radiation scatter. In contrast, Schade (9) measured radiation exposure at groin, knee, and feet, along with measurement at the eye and chest. He also showed that when a lead drape was applied from the patient to the floor, scatter radiation was reduced, specifically at groin, knee, and feet. Schade (9) observed clinically significant reductions in scatter radiation up to $99 \%$ by using lead shielding on the patient and from the table to the floor. Schade (9) concluded that the objective measurements of scattered radiation demonstrated that the surgeon can be exposed to dangerous levels of scatter radiation when imaging an average sized patient using a typical radiographic technique, and the clinically significant reduction in radiation exposure to the surgeon is achieved by using lead shielding starting on the patient and extending to the floor.

This prospective controlled study was undertaken to evaluate scatter radiation with the risk of whole body radiation exposure and protective measures to reduce scatter radiation in the upper and lower parts of the body in fluoroscopically guided interventional techniques.

\section{Methods}

Five hundred consecutive patients, undergoing interventional procedures, in an ambulatory surgery setting, by a single physician, were studied. The study was performed at a non-university interventional pain management practice. All the procedures were performed in a sterile environment in an operating room. Fluoroscopy units were operated by two certified radiological technologists. Inclusion criteria consisted of consecutive patients presenting for either diagnostic or therapeutic fluoroscopically guided interventional procedures. Exclusion criteria included pregnancy or allergy to iodine or any component of the injection.

Procedures were either performed in prone position or supine position. The procedures were performed in one of the two operating rooms with OEC $\AA$ fluoroscopic units available in each room (Compact 9600 or Compact 9800 OEC, Salt Lake City, Utah). The majority of the procedures included facet joint nerve blocks (cervical, thoracic or lumbar), epidurals (interlaminar or caudal), transforaminal epidurals (cervical or lumbar), percutaneous adhesiolysis, intercostal nerve blocks, and cervical or lumbar sympathetic blocks. Procedures were performed in a PA view and a lateral fluoroscopic view was utilized to confirm the needle placement when it was deemed necessary. Live fluoroscopy was also utilized whenever intravascular injection was suspected, and routinely for transforaminal epidural injections.

The mode utilized varied from pulsed-imaging to continuous fluoroscopic imaging. All the protective measures were incorporated, including lead shielding from the table to the floor covering the entire area of the beam, however, only half the length of the operating table.

Radiation exposure was monitored using a dosimetry badge with a lower limit of detectability of 1 mREM. One radiographic technologist allocated five badges to the physician prior to the procedures. These badges remained with the physician throughout the study. The badges were clearly marked as \#1 or CL on the neck collar inside the apron, \#2 or TR on the torso or outside the apron over the chest, $\# 3$ or $\mathrm{CH}$ on the chest pocket inside the apron, \#4 or RT over the belt of apron or groin area on the outside of the apron, and \#5 or GR inside the apron over the groin area attached to the belt.

The "outside" badge was placed outside the lead apron worn by the physician, which was of $0.5 \mathrm{~mm}$ thickness. The "inside" badge was placed on the neck at the thyroid level inside the apron in the thoracic area around $\mathrm{T} 4$, and over the groin area over the belt. The badges were all placed outside the radiation exposure area and outside the operating rooms, when they were not in use. The radiological technologist assigned to the study maintained a daily log of the patient's name, date of procedure, number of procedure(s), description of the procedure(s), fluoroscopic exposure time for each procedure, and total time for each patient.

Data were recorded on a database using Microsoft ${ }^{\circledR}$ Access. The SPSS version 9.0 statistical package was used to generate frequency tables. Results were considered statistically significant if the $p$ value was less than 0.05 . For comparison purposes, the data from a previous study (15) was utilized, which included 509 patients and was performed in the same manner by the same physician, except for there was no lead protection for the lower part of the body. 


\section{RESULTS}

Five hundred consecutive patients were included in the study. There were no exclusions. The data of the previous study without protective measures in the lower part of the body (15) were considered as Group I, whereas, the data of the current study of 500 patients were considered Group II.

Table 1 illustrates demographic features with age, gender, and body mass index in both groups. There were no significant differences noted among the groups.

Table 2 illustrates radiation exposure in both groups, with 509 patients and 827 procedures in Group I, and 500 patients in Group II with 865 procedures. Only the statistics for the procedures totaling more than 20 for the study period were included in the table. Average exposure per patient was $12.5 \pm 0.4$ seconds and $7.5 \pm$ 0.27 per procedure in Group I, compared to $8.9 \pm 0.4$ seconds per patient and $4.9 \pm$ 0.11 seconds per procedure in Group II. Group II showed significantly less radiation exposure compared to Group I.

Table 3 illustrates scatter radiation exposure in both groups at various levels of the body. As expected, the scatter radiation exposures were higher outside the lead aprons in both groups compared to inside the lead aprons. However, scatter radiation outside the apron was less in Group II compared to the previous study in Group I. In contrast, both groups were similar with respect to radiation exposure inside the apron, specifically at groin level.

\section{DISCUSSION}

A total of 500 patients in the current study, and 509 patients from a previous study (15) undergoing over 800 interventional pain management procedures in each group, in an ambulatory surgery center under fluoroscopy were evaluated. The results of this prospective study showed that exposure to the physician on average was $8.9 \pm 0.4$ seconds per patient, and $4.9 \pm$ 0.11 seconds per procedure. The exposure rates were significantly lower compared to the previous study (Group I). Radiation exposure in the current study ranged from a low of $2.8 \pm 0.27$ seconds for interlaminar or caudal epidural with a high of $11.8 \pm$ 2.39 seconds for percutaneous adhesiolysis among the commonly performed procedures. Scatter radiation outside the apron at chest was 313 mREM or 0.629 mREM per patient, and at groin was 176 mREM

Table 1. Demographic features

\begin{tabular}{|c|c|c|c|}
\hline & & Group I & Group II \\
\hline \multicolumn{2}{|c|}{ Number of patients } & 509 & 500 \\
\hline \multicolumn{2}{|c|}{ Number of procedures } & 827 & 865 \\
\hline \multicolumn{2}{|c|}{ Age (yrs) [ mean \pm SEM ] } & $50 \pm 0.6$ & $49 \pm 0.6$ \\
\hline \multirow{2}{*}{ Gender } & Male & $34 \%(175)$ & $40 \%(199)$ \\
\hline & Female & $66 \%(334)$ & $60 \%(301)$ \\
\hline \multicolumn{2}{|c|}{ Body mass index [ mean \pm SEM ] } & $28.6 \pm 0.3$ & $28.2 \pm 0.3$ \\
\hline
\end{tabular}

Table 2. Illustration of procedural characteristics and radiation exposure in seconds

\begin{tabular}{|l|c|c|}
\hline & $\begin{array}{c}\text { Group I } \\
\text { (509) }\end{array}$ & $\begin{array}{c}\text { Group II } \\
\text { (500) }\end{array}$ \\
\hline Per Patient & $12.5 \pm 0.4$ & $8.9^{\star} \pm 0.4$ \\
\hline Per Procedure & $\begin{array}{c}7.5 \pm 0.27 \\
(827)\end{array}$ & $\begin{array}{c}4.9^{\star} \pm 0.11 \\
(865)\end{array}$ \\
\hline $\begin{array}{l}\text { Facet Joint Nerve Blocks } \\
\text { (Cervical / Lumbar / Thoracic) }\end{array}$ & $\begin{array}{c}5.8 \pm 0.11 \\
(474)\end{array}$ & $\begin{array}{c}4.5^{\star} \pm 0.07 \\
(481)\end{array}$ \\
\hline $\begin{array}{l}\text { Epidurals } \\
\text { (Caudal / Interlaminar) }\end{array}$ & $\begin{array}{c}3.7 \pm 0.29 \\
(141)\end{array}$ & $\begin{array}{c}2.7^{\star} \pm 0.27 \\
(160)\end{array}$ \\
\hline Transforaminal \\
(Cervical / Lumbar) & $\begin{array}{c}10.6 \pm 0.60 \\
(92)\end{array}$ & $\begin{array}{c}8.4^{\star} \pm 0.5 \\
(102)\end{array}$ \\
\hline Percutaneous Adhesiolysis & $\begin{array}{c}18.9 \pm 1.72 \\
(50)\end{array}$ & $\begin{array}{c}11.8^{\star} \pm 2.39 \\
(35)\end{array}$ \\
\hline $\begin{array}{l}\text { Intercostal / Sympathetic Blocks } \\
\text { (Cervical or Lumbar) }\end{array}$ & $\begin{array}{c}7.4 \pm 1.09 \\
(27)\end{array}$ & $\begin{array}{c}4.0^{\star} \pm 0.35 \\
(35)\end{array}$ \\
\hline
\end{tabular}

( ) Indicates number of procedures

* Indicates significant difference

Procedures performed less than 20 were not listed in this table, however were utilized in calculating the exposure per procedure and patient Table 3. Illustration of scatter radiation exposure in mREM outside and
inside apron

\begin{tabular}{|l|c|c|}
\hline Location of Dosimetry Badge & Group I & Group II \\
\hline Number of patients & 509 & 500 \\
\hline Number of procedures & 827 & 865 \\
\hline Neck (Inside) & 0 & 0 \\
\hline Chest (outside) & 690 & 313 \\
\hline Chest (inside) & NA & 0 \\
\hline Groin (outside) & 1152 & 176 \\
\hline Groin (inside) & 15 & 13 \\
\hline
\end{tabular}

NA-Not available

or 0.352 mREM per patient respectively. This was lower compared to Group I without extra shielding. However, scatter radiation exposure was similar in both groups at the groin level (inside) (13 vs 15 mREM total or $0.029 \mathrm{mREM}$ per patient vs 0.026 mREM per patient).

This evaluation once again illustrates the importance of measuring radiation exposure in the upper and lower parts of the body. In addition, it also illustrates the need for utilizing protective measures in upper and lower parts of the body. Utilizing lead protection in the lower part also reduced scatter radiation exposure in the upper part of the body and outside the apron, however, failed to significantly reduce the radiation exposure inside the 
apron at groin level. Thus, in spite of appropriate lead protection for upper and lower parts of the body, and with precautionary measures employing the principles of ALARA with regard to time, distance, and shielding; there continues to be significant exposure to the groin inside the apron. It appears that while lower body protective measures reduce the scatter radiation exposure to the upper body, as well as outside the apron, it failed to reduce scatter radiation to the groin area. This is in contrast to the findings of Schade (9). However, the differences in these two investigations were Schade (9) evaluated scatter radiation exposure with procedures in lumbar region and the protection also extended the entire length of operating table, along with extension to the floor. He also utilized additional lead shielding on the patient. Thus, this study shows that physicians need to continue to find protective measures which will reduce radiation exposure inside the apron to minimal levels.

This study showed that radiation exposure is well within the established safety limits, in select interventional pain management settings. Further, scatter radiation exposure time have improved in the current study, compared to previous study. However, multiple variables should be taken into account prior to extrapolating these results for other locations and situations. Further, evaluations must be carried out to evaluate additional protective measures to reduce groin exposure of scattered radiation. Further, the shielding to protect the lower part of the body will not provide any protection in deep oblique or lateral exposures. Thus, fluoroscopic times and exposure risk depends not only on the technique applied for each procedure, it also depends on training of the individual, and the mode of fluoroscopy utilized. In fact, intermittent fluoroscopy or pulsed fluoroscopy will reduce the exposure, whereas, continuous fluoroscopy and visualization in multiple views and live fluoroscopy will increase the exposure risk. Additional factors include patient volume, number of regions treated in each patient, number of procedures performed in each region, and the experience of the physician, and radiographic technologist. Thus, it is almost impossible to calculate the absolute exposure to each individual physician, based on reports of controlled trials. Yet, the results of these controlled trials may be considered in evaluating in- dividual situations and cumulative exposure over a lifetime.

Further, controlled trials are required with additional protective measures to evaluate further potential reductions in scatter radiation exposure outside and inside the apron, specifically to the groin area.

\section{Conclusion}

This study, evaluating a total of 500 consecutive patients undergoing 865 interventional procedures, showed that protective measures have decreased scatter radiation exposure at all levels, outside and inside the apron, except for inside the groin. The scatter radiation exposure was measured in the upper part, as well as the lower part of the body outside and inside the apron. Protective measures included not only the lead apron, thyroid collar, following the principles of ALARA, but also lead protection for the lower part of the body. These protective measures have decreased scatter radiation exposure at all levels outside and inside the apron, except for inside the groin. Thus, it is concluded that there is scatter radiation exposure in upper and lower parts of the body, and it can be reduced with appropriate measures of protection in the neck, chest, but not in groin area.

\section{Author Affiliation: \\ Laxmaiah Manchikanti, MD \\ Medical Director \\ Pain Management Center of Paducah \\ 2831 Lone Oak Road \\ Paducah, Kentucky 42003 \\ E-mail: drm@apex.net}

\section{Kim A. Cash, RT}

Clinical Coordinator

Ambulatory Surgery Center

2831 Lone Oak Road

Paducah, Kentucky 42003

E-mail:kim@thepainmd.com

\section{Tammy L. Moss, RT}

Clinical Coordinator

Ambulatory Surgery Center

2831 Lone Oak Road

Paducah, Kentucky 42003

E-mail:kim@thepainmd.com

\section{Vidyasagar Pampati, MSc}

Statistician

Pain Management Center of Paducah

2831 Lone Oak Road

Paducah, Kentucky 42003

E-mail: sagar@painmd.com

\section{REFERENCES}

1. Manchikanti L, Singh V. Interventional pain management: Evolving issues for 2003. Pain Physician 2003; 6:125-137.

2. Fishman SM, Smith H, Meleger A et al. Radiation safety in pain medicine. Reg Anesth Pain Med 2000; 27:296-305.

3. Bogduk N: International Spinal Injection Society guidelines for the performance of spinal injection procedures. Part 1: Zygapophyseal joint blocks. Clin J Pain 1997; 13:285-302.

4. Manchikanti L, Staats P, Singh V et al. Evidence-based practice guidelines for interventional techniques in the management of chronic spinal pain. Pain Physician 2003; 6:3-80.

5. Manchikanti L (ed). Definitions of interventional procedures. In Interventional Pain Medicine: Documentation, Billing and Coding, ASIPP Publishing, Paducah KY 2002, pp 155-168.

6. Manchikanti L, Bakhit CE, Pakanati RR et al: Fluoroscopy is medically necessary for the performance of epidural steroids. Anesth Analg 1999; 89:1330-1331.

7. Botwin KP, Thomas S, Gruber RD et al: Radiation exposure of the spinal interventionalist performing fluoroscopically guided lumbar transforaminal epidural steroid injections. Arch Phys Med Rehabil 2002; 83:697-701.

8. Botwin KP, Freeman ED, Gruber RD et al: Radiation exposure to the physician performing fluoroscopically guided caudal epidural steroid injections. Pain Physician 2001; 4:343-348.

9. Schade CM: Fluoroscopic Safety.In Proceedings of the Worldwide Pain Conference. San Francisco, July 2000.

10. Manchikanti L, Cash KA, Moss TL et al: Radiation exposure to the physician in interventional pain management. Pain Physician 2002; 5:385-393.

11. Fredman B, Nun MB, Zohar E et al. Epidural steroids for treating "failed back surgery syndrome": Is fluoroscopy really necessary? Anesth Analg 1999; 88:367-372.

12. Stitz MY, Sommer HM. Accuracy of blind versus fluoroscopically guided caudal epidural injection. Spine 1999; 24:1371-1376.

13. Stojanovic MP, Vu TN, Caneris $O$ et al. The role of fluoroscopy in cervical epidural steroid injections: An analysis of contrast dispersal patterns. Spine 2002; 27:509-514.

14. Cluff R, Mehio AK, Cohen SP et al. The technical aspects of epidural steroid injections: A national survey. Anesth Analg 2002; 95:403-408.

15. Manchikanti L, Cash K, Moss T et al. Risk of whole body radiation exposure and protective measures in fluoroscopically guided Interventional Techniques: A Prospective Evaluation. BMC Anesthesiology 2003; in press.

16. National Council on Radiation Protection and Measurements. Ionizing Radiation Exposures of the Population of the United 
States. Report No. 116, Washington, DC, NCRP, 1993.

17. International Commission on Radiological Protection. Recommendation of the International Commission on Radiation Protection 26. Ann Int Commission Radiat Prot 1977; 1:1-53.

18. FDA Public Health Advisory: Avoidance of serious $x$-ray induced skin injuries to patients during fluoroscopically guided procedures. Rockville, MD, Food and Drug Administration, September 9, 1994.
19. Mahesh M. Fluoroscopy: Patient radiation exposure issues. Radiographics 2001; 21:1033-1045.

20. Lichtenstein DA, Klapholz L, Vardy DA et al. Chronic radiodermatitis following cardiac catheterization. Arch Dermatol 1996; 132:663-667.

21. Rosenthal LS, Beck TJ, Williams J et al. Acute radiation dermatitis following radiofrequency catheter ablation of atrioventricular nodal reentrant tachycardia. Pacing Clin Electrophysiol 1997; 20:1834-1839.
22. Sovik E, Klow NE, Hellesnes J et al. Radiation-induced skin injury after percutaneous transluminal coronary angioplasty: Case report. Acta Radiol 1996; 37:305-306.

23. Knautz MA, Abele DC, Reynolds TL. Radiodermatitis after transjugular intrahepatic portosystemic shunt. South Med / 1997; 90:352-356.

24. Vano E, Gonzalez L, Beneytez F et al. Lens injuries induced by occupational exposure in non-optimized interventional radiology laboratories. BrJ Radiol 1998; 71:728-733. 
